\title{
MORFOGÊNESE E ESTRUTURA DO CAPIM Cynodon spp. EM MONOCULTURA TANTO A PLENO SOL COMO EM SOMBREAMENTO ARTIFICIAL
}

\author{
Antônia Flávia Fernandes Torres* \\ Gynna Silva Azar \\ Fabileide de Sousa Costa*t* \\ José Rômulo de Sousa ${ }^{* * x+}$ \\ Maria Sandra Carneiro Barreto Campello ${ }^{*+*+* x}$
}

\begin{abstract}
RESUMO: Objetivou-se avaliar as características morfogênicas e estruturais do capim Cynodonspp. em diferentes idades de rebrota, em ambientes a pleno sol e sombreamento artificial sob pastejo de ovinos. 0 experimento foi realizado na zona rural de Geminiano (PI), no período de agosto de 2017 a julho de 2018. Para a densidade de perfilhamento, adotou-se 0 delineamento inteiramente casualizado em esquema fatorial $2 \times 2$, com dois tratamentos (pleno sol e sombreamento artificial) e duas condições de pastejo (pré e pós-pastejo), com quatro repetições. As demais variáveis foram analisadas no mesmo delineamento, em esquema fatorial $2 \times 3$ com os dois tratamentos e três idades de rebrota (7; 14 e 21 dias), com quatro repetições. A densidade de perfilhos foi aferida nas condições de pré e pós-pastejo, pela contagem do número total dos mesmos, utilizando-se um quadro de PVC com área de $0,25 \mathrm{~m}^{2}$, colocado aleatoriamente três vezes em cada piquete. Foram demarcados e avaliados oito perfilhos em cada piquete a cada sete dias após a saída dos animais para avaliação de suas características morfogênicas e estruturais. As características morfogênicas não sofreram influência dos sombreamentos e das idades de rebrota. Quanto às características estruturais, nos ambientes a pleno sol e sombreamento artificial houve diferença apenas nas variáveis NFV e NTF entre as idades de rebrota avaliadas, demonstrando que aos 21 dias de idade ocorre maior presença de folhas mortas e maior número de folhas. Recomenda-se manejar o cultivar de capim Cynodon spp. com idade de rebrota de 21 dias tanto nos ambientes a pleno sol como sombreados.
\end{abstract}

PALAVRAS-CHAVE: Gramínea; Luminosidade; Ovinos; Perfilho.

\section{MORPHOGENESIS AND STRUCTURE OF Cynodon spp. IN MONOCULTURE IN SUNSHINE AND IN ARTIFICIAL SHADE}

\footnotetext{
ABSTRACT: Morphogenic and structural characteristics of grass Cynodon spp. is evaluated at different regrowth ages in full sunshine and in artificial shade, for sheep pasture. The experiment was undertaken in the rural area of Geminiano PI Brazil, between August 2017 and July 2018. Sprout density was analyzed by randomized design at 2x2 factor, with two treatments (sunshine and artificial shade) and two pasture conditions (pre- and postpasture), with four replications. Other variables were analyzed within the same design, at $2 \times 3$, with two treatments and three regrowth ages (7, 14 and 21 days), with four repetitions. Tiller density was investigated in the pre and post-pasture conditions by counting their number by a $0.25 \mathrm{~m} 2 \mathrm{PVC}$ frame, randomly placed three times in each split. Eight tillers were marked and evaluated in each split every seventh day after the departure of the animals so that the morphogenic and structural characteristics could be evaluated. Morphogenic characteristics were not affected by shade and regrowth age. In the case of structural characteristics, differences occurred only in variables NFV and NTF in full sunshine and artificial shade, between regrowth ages. The above showed that there was a greater number of dead leaves and a greater number of leaves on the 21st day. Management of

Engenheira Agrônoma e Mestranda em Zootecnia pela Universidade Federal do Ceará, com ênfase na área de Nutrição Animal e Forragicultura, Ceará, Brasil. E-mail: flaviaftorres@outlook.com

* Engenheira Agrônoma com Mestrado e Doutorado em Ciência Animal. Docente Efetiva da Universidade Estadual do Piauí (UESPI), Piauí, Brasil.

${ }_{* * *}^{*}$ Engenheira Agrônoma formada pela Universidade Estadual do Piauí (UESPI), Piauí, Brasil.

***** Engenheiro Agrônomo formado pela Universidade Estadual do Piauí (UESPI), Piauí, Brasil.

* Médica Veterinária com Mestrado em Zootecnia. Docente na Universidade Estadual do Piauí (UESPI), Piauí, Brasil.
} 
cultivar Cynodon spp. at regrowth age of 21 days is recommended in modes sunshine and shade.

KEYWORDS: Grass; Luminosity; Ovine; Tillers.

\section{INTRODUÇÃO}

As pastagens compõem a principal fonte de alimentação dos rebanhos brasileiros, influenciando na qualidade de produtos, tornando 0 Brasil apto a competir pelo mercado internacional pelos baixos custos de produção. Entretanto, o manejo impróprio destas forrageiras e 0 declínio acentuado da fertilidade do solo contribuem para aumentar as áreas degradadas, influenciando diretamente na diminuição da produtividade e na composição botânica com 0 decorrer do tempo (CASTAGNARA et al., 2011).

0 sombreamento artificial é uma técnica utilizada para avaliar as respostas de gramíneas submetidas ao baixo nível de luminosidade, visando sua utilização em sistemas silvipastoris, por este proporcionar o uso múltiplo da terra, obtenção de pastagens sustentáveis e por ampliar as oportunidades de exploração de produtos vegetais e animais (ANDRADE et al., 2015).

Como forma de aumentar a produção, o nível de sombreamento e a maior disponibilidade de nutrientes no solo contribuem em melhorias nutricionais do pasto, que associados às melhores condições de conforto e bem-estar animal proporcionam 0 aumento no consumo de forragem e ganho de peso de animais submetidos ao pastejo (PACIULLO et al., 2009).

Dentre as forrageiras utilizadas para alimentação dos animais, o gênero Cynodon spp. é muito importante por apresentar alto potencial de produção de matéria seca, associado com elevado valor nutritivo, boa relação lâmina foliar: colmo e grande flexibilidade de uso nas áreas de pastagens (OLIVEIRA et al., 2014). Os capins deste gênero apresentam alta capacidade de produção e crescimento, tendo elevado potencial de uso como forrageira nas condições tropicais, sendo considerada uma forrageira resistente a sucessivos cortes, além de produzir matéria seca de qualidade em boas condições de manejo e adubação (MATOS et al., 2008).

Para avaliação das forrageiras, as mais relevantes formas para 0 estudo de sua dinâmica da produção primária são as avaliações das características morfogênicas e estruturais que permitem analisar 0 crescimento vegetal, bem como estimar a sua produção e taxa de acúmulo de matéria seca, sendo essencial para 0 conhecimento dos parâmetros referentes à ecofisiologia da planta, desde que sejam avaliados de acordo com seu regime de desfolhação em resposta ao pastejo de animais (DIFANTE et al., 2011).

0 entendimento da dinâmica de produção de forragem em um pasto vegetativo pode ser obtido pelo estudo de sua morfogênese, que é descrita por meio de três características básicas: 0 aparecimento de folhas, 0 alongamento de folhas e a duração de vida da folha, sendo a combinação dessas variáveis básicas responsável pelas principais características estruturais do pasto: tamanho da folha, densidade populacional de perfilhos e número de folhas vivas por perfilho (SANTOS et al., 2012).

0 conhecimento das características morfofisiológicas das gramíneas forrageiras possibilita 0 entendimento básico das respostas das plantas ao corte ou pastejo, determinando a sua capacidade de crescer em ambientes sombreados, demostrando 0 seu potencial de uso em sistemas silvipastoris (FREIRIA et al., 2014). 0 conhecimento dos padrões de perfilhamento das plantas permite identificar os métodos de manejo que possibilitem aumentar sua produtividade, assegurando sua persistência e longevidade pela contínua renovação populacional dos perfilhos (CAMINHA et al., 2010).

Visando uma contribuição para conservação do solo, melhorias na produtividade do pasto e a utilização das plantas forrageiras em um sistema silvipastoril, objetivou-se com esse trabalho avaliar as características morfogênicas e estruturais do capim Cynodon spp. em diferentes ambientes sob pastejo de ovinos. 


\section{METODOLOGIA}

A pesquisa foi desenvolvida na propriedade Santa Helena, na localidade Grossos, zona rural de Geminiano-PI, região semiárida do Estado do Piauí (707'42.38"S e 4123'35.89"W, altitude de $1176 \mathrm{~m}$ ), no período de agosto de 2017 a julho de 2018.0 clima da região, segundo a classificação de Köppen, é do tipo Bsh - quente e semiárido, com estação chuvosa no verão (ALVARES et al., 2014), com precipitação atingindo uma média anual de $696,6 \mathrm{~mm}$, sendo os meses de dezembro a março de maior incidência de chuvas, com a umidade relativa do ar em torno de $60 \%$, diminuindo sensivelmente na época da estiagem e com uma temperatura média anual de $30,5^{\circ} \mathrm{C}$ (MEDEIROS, 2000).

A área experimental foi formada pelo monocultivo do capim Cynodon spp., dividida em duas porções de $832 \mathrm{~m}^{2}$, sendo uma destinada ao ambiente a pleno sol e outra ao sombreamento artificial, subdivididas em quatro piquetes de 208 $\mathrm{m}^{2}$ cada, totalizando uma área cultivada de 0,16 ha. Para a densidade de perfilhamento adotou-se 0 delineamento inteiramente casualizado, consistindo em esquema fatorial $2 \times 2$, com dois ambientes (pleno sol e sombreamento artificial) e duas condições de pastejo (pré e pós-pastejo) com quatro repetições (piquetes), perfazendo 16 unidades experimentais. Para as demais variáveis, adotou-se 0 mesmo delineamento em esquema fatorial $2 \times 3$ com os mesmos dois ambientes, três idades de rebrota $(7 ; 14$ e 21 dias) com quatro repetições (piquetes), totalizando 24 unidades experimentais.

Foram realizadas coletas de amostras de solo de $0-20 \mathrm{~cm}$ de profundidade, as quais foram submetidas à análise química no Laboratório Agronômico da Unithal, em Campinas - SP, sendo encontrados os resultados para $\mathrm{pH}=6,0 ; \mathrm{M} .0 .=1,5 \%$; $\mathrm{P}=17,0 \mathrm{mg} / \mathrm{dm}^{3} ; \mathrm{K}=0,31 \mathrm{cmol} ; \mathrm{Ca}=3,6 \mathrm{cmol} ; \mathrm{Mg}=$ $1,4 \mathrm{cmol} ; \mathrm{H}+\mathrm{Al}=0,9 \mathrm{cmol} ; \mathrm{SB}=5,31 \mathrm{cmol} ; \mathrm{T}=6,21$ $\mathrm{cmol} ; \mathrm{V} \%=85,51 \%$ e SO4 $=9,0 \mathrm{mg} \cdot \mathrm{dm}^{3}$.

De acordo com a interpretação da análise, não houve necessidade de realizar calagem do solo, sendo feita apenas uma aplicação de $50 \mathrm{~kg} \cdot \mathrm{ha}^{-1}$ de nitrogênio, que foi aplicado na forma de ureia, em cobertura, sete dias após o corte de uniformização e após a saída dos animais dos piquetes.

A área do sombreamento artificial foi composta por telas tipo "sombrite", compreendendo um nível de $50 \%$ de sombreamento, permitindo $50 \%$ de passagem de luz. 0 sombrite abrangeu $35 \%$ da área de cada piquete, para simular 0 sombreamento das árvores da caatinga, onde foi formado por três faixas de 1,5 m x 16 m, espaçadas a uma distância de $1,5 \mathrm{~m} \mathrm{e}$ implantadas paralelamente na área, a uma altura de aproximadamente $2 \mathrm{~m}$, para facilitar 0 deslocamento no local.

Como a pastagem já se encontrava formada na área, foi realizado um corte de uniformização a $20 \mathrm{~cm}$ do solo, em intervalos de sete dias entre os piquetes, antes de iniciar o pastejo dos animais, de forma que proporcionou melhor padronização da área. As avaliações iniciaram após a saída dos animais de cada piquete, para a observação do desenvolvimento da gramínea em diferentes estádios de rebrota. 0 período de ocupação e de descanso foi de sete e 21 dias, respectivamente.

Os ovinos utilizados foram machos sem padrão de raça definida (SPRD), com uma faixa de idade em torno de três meses, um peso inicial variando de 10 a $15 \mathrm{~kg}$ por animal, com uma taxa de lotação de 3,2 UA.ha ${ }^{-1}$ (COSTA et al., 2015). Foram utilizados cinco animais por tratamento, compreendendo um total de dez ovinos. Todos os animais foram vermifugados e vacinados antes de iniciar as avaliações do experimento.

Adotou-se o manejo intensivo, em que os animais eram soltos nos piquetes pela manhã, passando 0 dia todo com sal e água à vontade $\mathrm{e}$ no final da tarde, eram recolhidos ao aprisco onde passavam a noite e os mesmos tinham acesso a $200 \mathrm{~g}$ de ração por dia.animal ${ }^{-1}$, sendo esta composta de 30 , 30 e $40 \%$ de soja, trigo e milho, respectivamente. Vale ressaltar que o trabalho foi aprovado pela Comissão de Ética no Uso Animal (CEUA), com protocolo de número 0068/2017.177. 
Para a avaliação morfogênica e estrutural do capim, oito perfilhos em cada piquete foram demarcados e avaliados em intervalos de sete dias, após a saída dos animais nos piquetes, totalizando quatro avaliações por piquete e compreendendo 32 perfilhos por tratamento.

Os perfilhos foram identificados com fios coloridos e fixadas estacas de madeira a fim de proporcionar melhor visualização no campo. Registraram-se os dados referentes ao aparecimento do ápice foliar, dia da exposição da lígula, comprimento do colmo, comprimento da lâmina foliar expandida e em expansão, número de folhas por perfilho e número de folhas vivas, mortas e em senescência. A partir dessas informações, foram calculadas as variáveis conforme Pereira et al. (2011):

- taxa de aparecimento de folhas (TAPF): número total de folhas no perfilho dividido pelo período de rebrotação, expressa em folhas.dia ${ }^{-1}$;

- filocrono (FILO): inverso da taxa de aparecimento de folhas, expresso em dias.folha ${ }^{-1}$;

- taxa de alongamento de folhas (TALF): diferença entre os comprimentos final e inicial das folhas emergentes divididas pelo número de dias entre

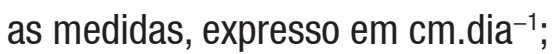

- taxa de alongamento do colmo (TALC): diferença entre os comprimentos final e inicial do colmo dividido pelo número de dias entre as medidas, expresso em cm.dia ${ }^{-1}$;

- número de folhas vivas/perfilho (NFV): número médio de folhas em alongamento e alongados por perfilho, que não apresentam sinal de senescência;

- número de folhas em senescência (NFS): número de lâminas com até $50 \%$ de sua área foliar amarelecida;

- número de folhas mortas (NFM): contagem das folhas com mais de $50 \%$ de sua área foliar amarelecida;

- número total de folhas (NTF): contabilização do número de folhas em expansão, expandidas, se- nescentes e mortas dos perfilhos;

- comprimento final da lâmina foliar (CFLF): medição das folhas completamente expandidas, desde sua inserção na lígula até 0 ápice foliar, expresso em cm;

- comprimento final do colmo (CFC): medição da altura final do colmo, expresso em cm;

- duração de vida das folhas (DVF): tempo decorrido do surgimento de uma folha e o início de sua senescência, DVF = NFV x filocrono (dias).

A densidade de perfilhos foi aferida nas condições de pré e pós-pastejo, pela contagem do número de perfilhos totais utilizando-se um quadro de PVC com área de $0,25 \mathrm{~m}^{2}$, lançado aleatoriamente três vezes em cada piquete, durante dois ciclos.

Os dados coletados foram submetidos à análise da variância para observação da existência ou não de interação dos ambientes e as idades de rebrota, sobre a morfogênese e estrutura e a interação dos ambientes e condições de pastejo, sobre a densidade de perfilhamento do Cynodon spp. As médias obtidas foram comparadas pelo teste de Tukey a $5 \%$ de probabilidade, pelos procedimentos ANOVA e GLM do SAS (2000). Além disso, foi realizada a análise de regressão para encontrar uma relação entre as variáveis estudadas.

\section{RESULTADOS}

Analisando a taxa de alongamento de folhas e a taxa de alongamento do colmo do pasto de Cynodon spp., observou-se que os tratamentos não exerceram influência significativa para estas variáveis, não diferindo entre os ambientes e entre as idades de rebrota $(P>0,05)$. Com relação à TALF, quando cultivada no ambiente sombreado, esta apresentou condição linear e crescente em detrimento do ambiente a pleno sol, que demonstrou decréscimo dos valores com 0 aumento das idades de rebrota (Figura 1), com valores médios de 3,41 e 3,13 cm.dia ${ }^{-1}$, respectivamente. 


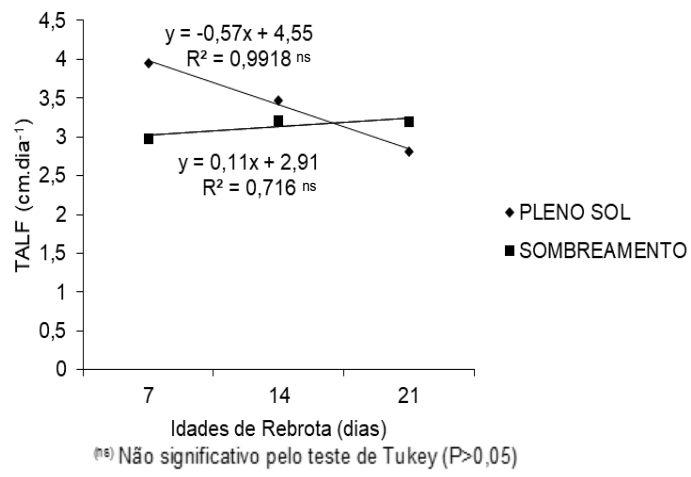

Figura 1. Taxa de alongamento de folhas do capim Cynodon spp. em monocultura tanto a pleno sol como em sombreamento.

Os valores médios da TALC $\left(0,59 \mathrm{~cm} \cdot \mathrm{dia}^{-1}\right.$ no ambiente a pleno sol e $0,62 \mathrm{~cm} \cdot \mathrm{dia}^{-1}$, no ambiente sombreado) comportaram-se de forma semelhante aos da TALF, demonstrando que no ambiente sombreado houve condição linear e crescente com 0 incremento das idades de rebrota e uma condição linear e decrescente, quando cultivado a pleno sol (Figura 2).

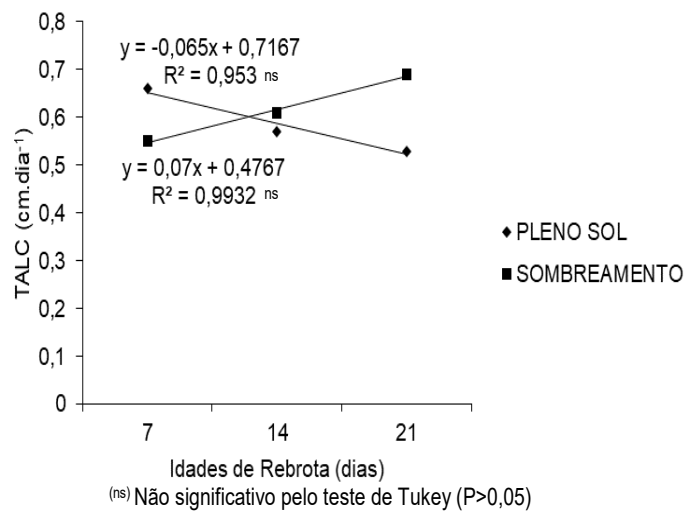

Figura 2. Taxa de alongamento do colmo do capim Cynodon spp. em monocultura tanto a pleno sol como em sombreamento.

A TAPF do capim Cynodon spp. não diferiu entre os ambientes e idades de rebrota ( $P>0,05)$, apresentando valores médios de 0,32 e 0,36 folhas.dia ${ }^{-1}$ em pleno sol e no sombreamento, respectivamente (Figura 3), observando-se que em ambos os ambientes ocorreu uma condição linear e decrescente com 0 avanço das idades de rebrota.

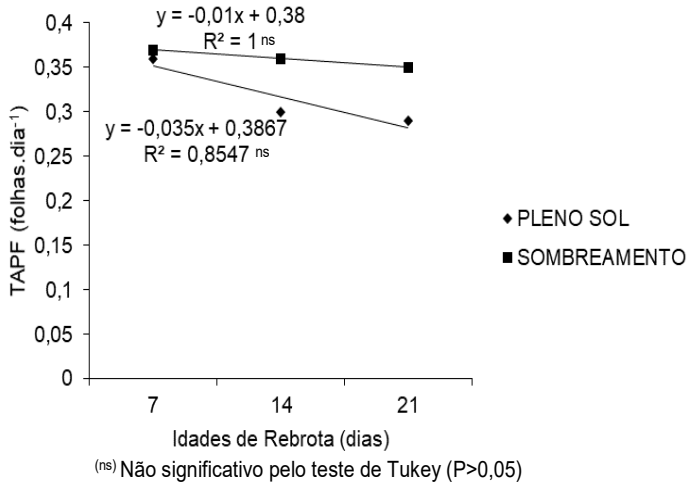

Figura 3. Taxa de aparecimento de folhas do capim Cynodon spp. em monocultura tanto a pleno sol como em sombreamento.

Para o FILO, que é o inverso da TAPF, não foi constatado significância para os efeitos dos fatores estudados e para interação entre estes ( $P>0,05)$, em que os dois ambientes apresentaram condição polinomial com 0 incremento das idades de rebrota, com as equações: $y=-0,245 x^{2}+1,195 x+2,23$, para 0 ambiente a pleno sol e $y=-0,375 x^{2}+1,755 x+1,46$, para 0 sombreamento (Figura 4).

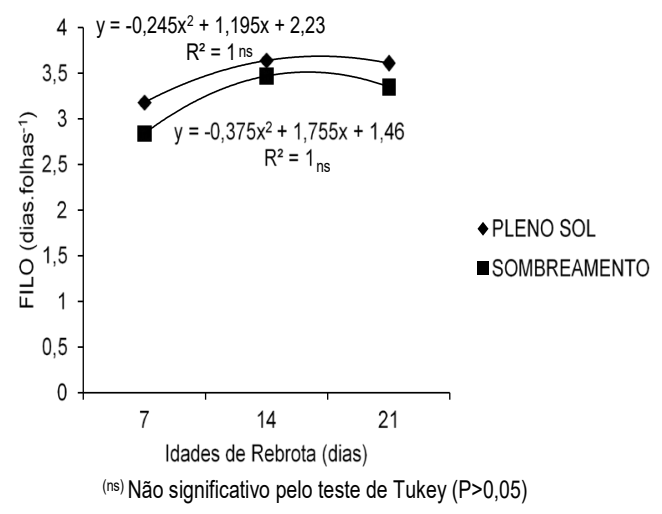

Figura 4. Filocrono do capim Cynodon spp. em monocultura tanto a pleno sol como em sombreamento.

Em relação à duração de vida da folha, a interação não foi significativa entre os ambientes e idades de rebrota $(P>0,05)$, demonstrando uma condição polinomial nos ambientes avaliados com valores médios de DVF da forrageira de 24,85 e 25,03 dias, para pleno sol e sombreamento, respectivamente (Figura 5). 


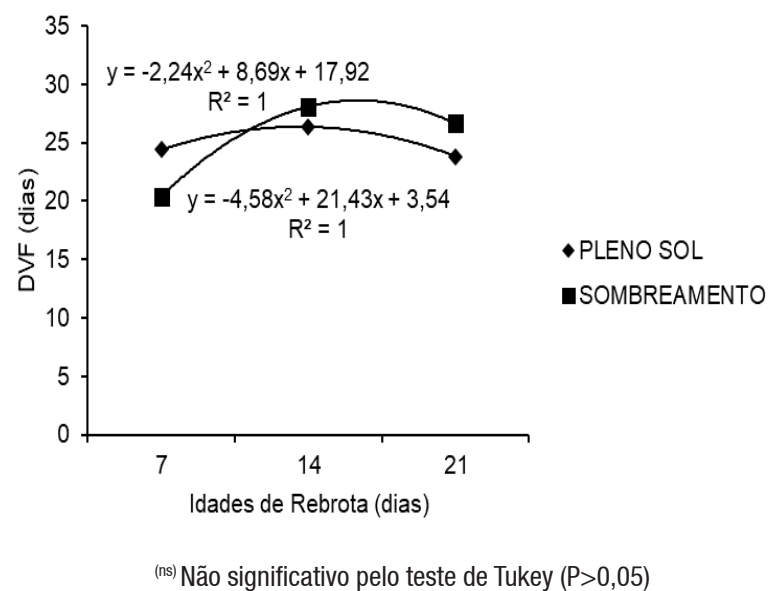

Figura 5. Duração de vida das folhas do capim Cynodon spp. em monocultura tanto a pleno sol como em sombreamento.

Os valores de NFV e NFS do capim Cynodon spp. não variaram com os ambientes, tampouco com a interação entre as idades de rebrota $(P>0,05)$, com médias de 7,09 folhas vivas e 0,51 folhas senescentes, no ambiente a pleno sol e de 7,83 folhas vivas e 0,62 folhas senescentes, sob sombreamento artificial (Tabela 1).

As médias de NFM e NTF do Cynodon spp. não diferiram significativamente entre os ambientes avaliados, tendo diferença apenas com relação às idades de rebrota (Tabela 1). No ambiente a pleno sol, o pasto de Cynodon spp. apresentou maior NFM aos 21 dias de idade (5,04 folhas) e menor valor aos sete dias (0,82 folhas), não diferindo ambos dos 14 dias de idade (2,26 folhas). Em relação ao sombreamento, 0 menor valor de NFM foi encontrado aos sete dias de idade e o maior, aos 21 dias, com valores de 0,53 e 3,85 folhas, respectivamente $(P<0,05)$.

Tabela 1. Características estruturais do capim Cynodon spp., cultivado a pleno sol e em sombreamento sob diferentes idades de rebrota

\begin{tabular}{lccccc}
\hline \multirow{5}{*}{ Ambientes } & \multicolumn{6}{c}{ Idades de rebrota } \\
\cline { 2 - 6 } & $\begin{array}{c}\mathbf{7} \text { dias } \\
\text { de } \\
\text { idade }\end{array}$ & $\begin{array}{c}\mathbf{1 4} \text { dias } \\
\text { de idade }\end{array}$ & $\begin{array}{c}\mathbf{2 1} \text { dias } \\
\text { de } \\
\text { idade }\end{array}$ & Média & CV(\%) \\
\hline \multicolumn{5}{c}{${ }^{*} N F V\left(n^{0}\right)$} \\
\hline Pleno sol & 7,50 & 7,19 & 6,57 & 7,09 & 14,05 \\
Sombreamento & 7,19 & 8,16 & 8,13 & 7,83 & 13,91
\end{tabular}

\begin{tabular}{|c|c|c|c|c|c|}
\hline Média & 7,35 & 7,68 & 7,35 & & \\
\hline CV $(\%)$ & 14,00 & 10,44 & 17,02 & & \\
\hline \multicolumn{6}{|c|}{${ }^{\star} \mathrm{NFS}\left(\mathrm{n}^{0}\right)$} \\
\hline Pleno sol & 0,26 & 0,79 & 0,47 & 0,51 & 12,68 \\
\hline Sombreamento & 0,47 & 0,60 & 0,79 & 0,62 & 22,70 \\
\hline Média & 0,37 & 0,70 & 0,63 & & \\
\hline CV $(\%)$ & 82,49 & 69,03 & 83,56 & & \\
\hline \multicolumn{6}{|c|}{${ }^{*} \mathrm{NFM}\left(\mathrm{n}^{0}\right)$} \\
\hline Pleno sol & $0,82 \mathrm{~b}$ & $2,26 a b$ & $5,04 \mathrm{a}$ & 2,71 & 55,03 \\
\hline Sombreamento & $0,53 \mathrm{c}$ & $1,91 \mathrm{~b}$ & $3,85 \mathrm{a}$ & 2,10 & 32,80 \\
\hline Média & 0,68 & 2,09 & 4,45 & & \\
\hline CV $(\%)$ & 56,40 & 45,94 & 38,78 & & \\
\hline \multicolumn{6}{|c|}{${ }^{*} \operatorname{NTF}\left(n^{0}\right)$} \\
\hline Pleno sol & $8,57 \mathrm{~b}$ & $10,22 a b$ & $12,06 \mathrm{a}$ & 10,28 & 13,72 \\
\hline Sombreamento & $8,19 \mathrm{~b}$ & $10,66 a b$ & $12,75 \mathrm{a}$ & 10,53 & 17,05 \\
\hline Média & 8,38 & 10,44 & 12,41 & & \\
\hline CV(\%) & 15,90 & 15,00 & 15,29 & & \\
\hline \multicolumn{6}{|c|}{${ }^{\star} \mathrm{CFLF}(\mathrm{cm})$} \\
\hline Pleno sol & 7,01 & 7,45 & 5,28 & 6,58 & 37,75 \\
\hline Sombreamento & 6,31 & 6,54 & 6,00 & 6,28 & 40,60 \\
\hline Média & 6,66 & 7,00 & 5,64 & & \\
\hline $\mathrm{CV}(\%)$ & 45,84 & 42,66 & 15,81 & & \\
\hline \multicolumn{6}{|c|}{${ }^{*} \mathrm{CFC}(\mathrm{cm})$} \\
\hline Pleno sol & 29,40 & 32,63 & 35,67 & 32,57 & 23,48 \\
\hline Sombreamento & 32,31 & 37,02 & 42,97 & 37,43 & 26,50 \\
\hline Média & 30,86 & 34,83 & 39,32 & & \\
\hline CV (\%) & 21,98 & 24,84 & 27,21 & & \\
\hline
\end{tabular}

Médias seguidas de letras diferentes, na linha, diferem $(\mathrm{P}<0,05)$ pelo teste de Tukey.

*NFV - Número de folhas vivas; *NFS - Número de folhas senescentes; *NFM - Número de folhas mortas; *NTF - Número total de folhas; *CFLF - Comprimento final da lâmina foliar; ${ }^{*} \mathrm{CFC}$ - Comprimento final do colmo.

Quanto ao NTF, tanto no ambiente a pleno sol como no sombreamento, os maiores valores foram encontrados aos 21 dias de idade, com 12,06 e 12,75 folhas, respectivamente e os menores, aos sete dias, com 8,57 folhas a pleno sol e 8,19 folhas no sombreamento, não diferindo ambos dos 14 dias de idade.

Os valores do comprimento final da lâmina foliar e do comprimento final do colmo do capim 
Cynodon spp. não variaram com os ambientes, tampouco com a interação entre as idades de rebrota ( $P>0,05)$ (Tabela 1), com médias de CFLF de 6,58 e $6,28 \mathrm{~cm}$ e de CFC de 32,57 e $37,43 \mathrm{~cm}$, em pleno sol e sombreamento artificial, respectivamente.

Não foi constatado variação na densidade de perfilhos de Cynodon spp. entre os ambientes e entre as condições de pastejo ( $P>0,05)$, com valores de 3.715.200 e 4.300.000 perfilhos.ha ${ }^{-1}$ no ambiente a pleno sol e de 3.270 .000 e 3.566 .800 perfilhos.ha ${ }^{-1}$ no sombreamento, em condições de pré e pós-pastejo, respectivamente (Figura 6).

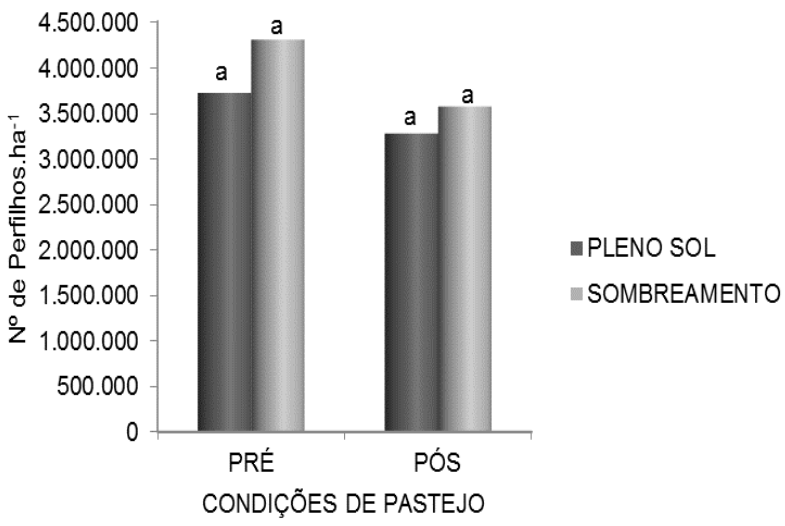

Figura 6. Densidade de perfilhamento do capim Cynodon spp, em condições de pré e pós-pastejo. Letras iguais não diferem $(P>0,05)$ pelo teste de Tukey.

\section{DISCUSSÃO}

A variável TALF do capim cultivado sob sombreamento artificial foi maior quando comparada ao ambiente a pleno sol aos 21 dias de idade, por ser característica das plantas terem maior desenvolvimento da parte aérea com 0 decorrer do tempo a fim de aumentar a competitividade e eficiência de fixação de $\mathrm{CO}_{2}$ quando são submetidas a condições de sombreamento, fator este associado à necessidade que a planta possui de captar luz em situações de baixa incidência solar (MARTINS et al., 2014). Além disso, a presença de sombra proporciona uma temperatura mais amena e um solo com maior umidade, podendo ter contribuído para 0 aumento na taxa de mineralização de nitrogênio nessa área, decompondo a matéria orgânica mais rapidamente $\mathrm{e}$ promovendo maior ciclagem de nutrientes (PACIULLO et al., 2008) quando comparado ao ambiente a pleno sol, o que explica a condição linear e crescente do ambiente sombreado com 0 avanço das idades de rebrota.

Com relação à TALC, sabe-se que quando as plantas são cultivadas à sombra, é comum 0 incremento desta variável por ser uma maneira de compensar a redução de luminosidade, culminando no estiolamento destas plantas, que elevam suas folhas no dossel forrageiro na busca por radiação solar (PACIULL0 etal., 2008), o que pode ser observado neste estudo pelo aumento do alongamento dos colmos no ambiente sombreado com o decorrer do tempo, com uma diferença de $0,16 \mathrm{~cm}$. dia $^{-1}$ entre os tratamentos quanto à TALC aos 21 dias de idade.

Quanto à TAPF, esta é uma das características mais importantes da morfogênese de plantas, por influenciar diretamente as principais características estruturais (densidade populacional de perfilhos, número de folhas vivas e tamanho das folhas), portanto, sofre efeito reduzido das condições de manejo e do meio de cultivo (MACEDO et al., 2010). Com isso, infere-se que os dados encontrados foram semelhantes aos encontrados por Paciullo et al. (2005) que, ao avaliar a TAPF do capim Cynodon dactylon em diferentes estações do ano, encontraram valores médios de 0,327 folhas.dia.perfilho-1 ${ }^{-1}$, durante a estação de primavera.

Apesar de não ser observado diferença significativa para a variável FILO do capim Cynodon spp., os valores médios encontrados foram iguais a 3,48 e 3,22 dias.folha ${ }^{-1}$ no ambiente a pleno sol e no sombreamento, respectivamente, dados que representam a plasticidade que esta gramínea apresenta em adaptar-se a ambientes sombreados sem afetar diretamente seu desenvolvimento, demonstrando sua capacidade de utilização em sistemas silvipastoris para manutenção de áreas de pastagens. Os dados encontrados são semelhantes aos de Ziech et al. (2016), que ao avaliar pastagens 
estabelecidas com o capim coastcross-1 (Cynodon dactylon), verificaram o valor médio do FILO de 3,1 dias.folha ${ }^{-1}$.

Com relação à DVF, a determinação desta variável é importante para a definição da frequência e da intensidade de pastejo, buscando evitar perdas por senescência ou morte das folhas, em que os valores encontrados neste estudo foram de 24,85 e 25,03 dias, para pleno sol e sombreamento, respectivamente, valores semelhantes ao encontrado por Zeich et al. (2016), que ao avaliar o capim coastcross-1 (Cynodon dactylon), encontraram uma média de DVF de 25,8 dias.

0 maior número de folhas senescentes e mortas com 0 avanço das idades de crescimento da planta forrageira pode ser justificadas pelo processo de desenvolvimento das folhas que acarretam em sua senescência, sendo um fator que sofre influência de variáveis ambientais, como 0 manejo da colheita, disponibilidade de nitrogênio no solo e os fatores genéticos relacionados à planta (PEREIRA et al., 2011). Ou seja, com o passar do tempo, as folhas priorizam 0 desenvolvimento e expansão de folhas novas, o que culmina em uma estacionalidade nas folhas baixeiras, que passam a entrar em processo de senescência após cessarem seu crescimento. A partir destes dados, pode-se observar que há maior presença de folhas mortas no decorrer do tempo, devendo ser preconizada a entrada dos animais no pasto em um período em que há maior presença de material verde, para obter maior eficiência de pastejo e maior oferta de alimento com maior valor nutritivo e de grande aceitabilidade pelos animais.

Os resultados do NTF encontrados assemelham-se aos de Pereira et al. (2011) que, ao avaliar as características estruturais do capim tifton-85 (Cynodon spp.), observaram que o NTF aumentou linearmente com a altura das plantas ao tempo de corte, com valores de 13,09 e 15,88 folhas para plantas colhidas com 30 e $50 \mathrm{~cm}$, respectivamente. Desta forma, percebe-se que quando as plantas são mantidas em condições ambientais adequadas, aumenta-se 0 número total de folhas nos perfilhos à medida que ocorre um incremento no período de rebrotação.

Para a variável CFLF, esperava-se que houvesse maiores incrementos no ambiente sombreado quando comparado ao pleno sol, visto que é comum ocorrer maior desenvolvimento de folhas em situações de baixa luminosidade, pois a menor radiação e temperatura diminuem 0 acúmulo de graus-dias, 0 que influencia diretamente a morfogênese das plantas forrageiras (SOARES et al., 2009). Mesmo com a ausência de diferimento entre os tratamentos, pode-se observar que ocorreu aumento de $0,72 \mathrm{~cm}$ no comprimento das lâminas foliares das plantas que estavam sob sombreamento artificial, aos 21 dias de idade.

Com relação ao $\mathrm{CFC}$, maiores incrementos podem estar relacionados com a formação de um arranjo espacial na estrutura do dossel forrageiro, podendo ocasionar 0 tombamento das plantas, que poderia dificultar a seletividade e pastejo dos animais na área (TEIXEIRA et al., 2014). Com base nesta afirmação, o CFC é uma variável de grande importância para determinar a entrada e saída dos animais no piquete, de forma a proporcionar melhor aproveitamento da gramínea, sem comprometer o seu desempenho.

Mesmo com a ausência de diferimento dos tratamentos com relação à densidade de perfilhos, pode-se observar que o sombreamento apresenta valores próximos quando comparado ao ambiente a pleno sol, pois na presença de sombra a planta não tende a estimular o perfilhamento, com uma diminuição da produção de fotoassimilados para as partições do vegetal, tais como colmo e bainha (MARTINS et al., 2014). Dessa forma, ressalta-se a importância da luz como estímulo ao desenvolvimento das gemas basais que promovem 0 aparecimento de novos perfilhos em áreas de pastagens.

As menores quantidades de perfilhos, em condições de pós-pastejo, podem ser explicadas pelas desfolhações frequentes ocasionadas pela intensidade do pastejo que contribuem para a diminuição do perfilhamento e essa diminuição, de acordo com 
Cutrim Junior et al. (2011), pode reduzir a persistência da pastagem, fator que dependerá da quantidade de material remanescente presente na área, para que ocorra o restabelecimento do pasto após desfolhação.

\section{CONCLUSÃO}

Recomenda-se manejar o cultivar de capim Cynodon spp. com idade de rebrota de 21 dias tanto nos ambientes a pleno sol como sombreados.

\section{AGRADECIMENTOS}

Ao CNPq pela concessão de bolsa de iniciação científica para a primeira autora.

\section{REFERÊNCIAS}

ALVARES, C.A. et al. Köppen's climate classication map for Brazil. Meteorologische Zeitschrift, Stuttgart, v. 22, n. 6, p. 711-728, 2014.

ANDRADE, W.R.; ALVES, D.D.; ROCHA, H.C.M. Características morfológicas e produtivas do capim-buffel submetido ao sombreamento artificial. In: FÓRUM DE ENSINO, PESQUISA, EXTENSÃO E GESTÃO, 9., 2015, Montes Claros. Anais... Montes Claros:FEPEG, 2015.

CAMINHA, F.0. et al. Estabilidade da população de perfilhos de capim-marandu sob lotação contínua e adubação nitrogenada. Pesquisa Agropecuária Brasileira, Brasília - DF, v. 45, n. 2, p. 213-220, 2010.

CASTAGNARA, D.D. et al. Produção de forragem, características estruturais e eficiência de utilização do nitrogênio em forrageiras tropicais sob adubação nitrogenada. Semina: Ciências Agrárias, Londrina PR, v. 32, n. 4, p. 1637-1648, 2011.

COSTA, J.V. et al. Comportamento em pastejo e ingestivo de caprinos em sistema silvipastoril.

Revista Ciência Agronômica, Fortaleza - CE, v. 46, n. 4, p. 865-872, 2015.

CUTRIM JUNIOR, J.A.A. et al. Características estruturais do dossel de capim-tanzânia submetido a três frequências de desfolhação e dois resíduos póspastejo. Revista Brasileira de Zootecnia, Viçosa MG, v. 40, n. 3, p. 489-497, 2011.

DIFANTE, G.S. et al. Características morfogênicas e estruturais do capim-marandu submetido a combinações de alturas e intervalos de corte. Revista Brasileira de Zootecnia, Viçosa - MG, v. 40, n. 5, p. 955-963, 2011.

FREIRIA, L.B. et al. Impacto da adubação nitrogenada nas características morfofisiológicas de gramíneas do gênero Brachiaria e Cynodon em pastejo e corte. PUBVET, Maringá - PR, v. 8, n. 8, p. 830-974, 2014.

MACED0, C.H.O. et al. Características agronômicas, morfogênicas e estruturais do capim Panicum maximum cv. Mombaça sob desfolhação intermitente. Revista Brasileira de Saúde e Produção Animal, Salvador - BA, v. 11, n. 4, p. 941-952, 2010.

MARTINS, A.D. et al. Relação do nível de sombreamento artificial e da adubação sobre 0 desenvolvimento da forrageira Urochloa brizantha cv. Marandu. Revista Brasileira de Saúde e Produção Animal, Salvador - BA, v. 15, n. 4, p. 994-1005, 2014.

MATOS, A.T. et al. Desempenho agronômico de capim tifton 85 (Cynodon spp.) cultivado em sistemas alagados construídos utilizados no tratamento de água residuária de laticínios. Revista Ambi-Água, Taubaté - SP, v. 3, n. 1, p. 43-53, 2008.

MEDEIROS, R.M. Estudo agrometeorológico para o Estado do Piauí. Secretaria do Meio Ambiente e Recursos Hídricos do Estado do Piauí, Teresina - PI, 2000. 138p.

OLIVEIRA, E.R. et al. Degradabilidade ruminal da matéria seca de folhas e colmo de genótipos de Cynodon spp. em quatro idades de rebrota. Semina: 
Ciências Agrárias, Londrina - PR, v. 35, n. 5, p. 2659-2672, 2014.

PACIULLO, D.S.C. et al. Morfogênese, características estruturais e acúmulo de forragem em pastagem de Cynodon dactylon, em diferentes estações do ano.

Ciência Animal Brasileira, Goiânia - G0, v. 6, n. 4, p. 233-241, 2005.

PACIULLO, D.S.C. et al. Características do pasto e desempenho de novilhas em sistema silvipastoril e pastagem de braquiária em monocultivo. Pesquisa Agropecuária Brasileira, Brasília - DF, v. 44, n. 11, p. 1528-1535, 2009.

PACIULLO, D.S.C. et al. Crescimento de capimbraquiária influenciado pelo grau de sombreamento e pela estação do ano. Pesquisa Agropecuária Brasileira, Brasília - DF, v. 43, n. 7, p. 917-923, 2008.

PEREIRA, 0.G. et al. Características morfogênicas e estruturais do capim-tifton 85 sob doses de nitrogênio e alturas de corte. Revista Brasileira de Zootecnia, Viçosa - MG, v. 40, n. 9, p. 1870-1878, 2011.

SANTOS, M.E.R. et al. Correlações entre características morfogênicas e estruturais em pastos de capim-braquiária. Ciência Animal Brasileira, Goiânia-G0, v. 13, n. 1, p. 49-56, 2012.

SOARES, A.B. et al. Influência da luminosidade no comportamento de onze espécies forrageiras perenes de verão. Revista Brasileira de Zootecnia, Viçosa MG, v. 38, n. 3, p. 443-451, 2009.

STATISTICAL ANALYSIS SISTEM. SAS. User's Guide.

Version. Cary, NC: SAS Institute, 2000.

TEIXEIRA, F.A. et al. Estratégias de adubação nitrogenada, características morfogênicas e estruturais em pastos de Brachiaria decumbens diferidos por 95 dias. Semina: Ciências Agrárias, Londrina - PR, v. 35, n. 2, p. 987-998, 2014.

ZIECH, M.F. et al. Responses of Cynodon pastures mixed with forage peanut in Southwestern Paraná,
Brazil. Semina: Ciências Agrárias, Londrina, PR, v. 37, n. 6, p. 4193-4202, 2016.

Recebido em: 08/07/2019 Aceito em: 27/09/2019 